Conservation and Society 18(2): 71-76, 2020

Special Section: Rewilding 'Feral Political Ecologies'

\title{
Feral Political Ecologies?: The Biopolitics, Temporalities and Spatialities of Rewilding
}

\author{
Sophie Wynne-Jones ${ }^{a}$, Cara Clancy ${ }^{b}$, George Holmes ${ }^{c}$, Kieran O’Mahonyd, and Kim J Warde,\# \\ a School of Natural Sciences, Bangor University, Bangor, Wales \\ ${ }^{\mathrm{b}}$ School of Geography, Earth and Environmental Science, Plymouth University, Plymouth, UK \\ ${ }^{\mathrm{c} S}$ School of Earth and Environment, University of Leeds, Leeds, UK

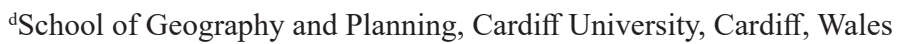

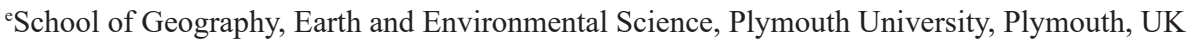

\#Corresponding author. E-mail: Kim.ward@plymouth.ac.uk

\section{INTRODUCTION}

In an era of escalating environmental change and degradation, rewilding has emerged as an innovative, hopeful, and increasingly popular form of conservation capturing the imagination of both publics and professionals alike, but equally courting controversy (Lorimer 2015; Jepson 2018; Pettorelli et al. 2018). Rewilding is aligned with restorative practices promoting landscape fluidity, connectivity and non-equilibrium ecologies (Manning et al. 2009; Zimmerer 2000; Lindenmayer and Fischer 2013). However, given its emphasis on nonhuman autonomy, and a reduction in human intervention and control, rewilding can be seen as a distinct and novel strategy distinguished from traditional forms of ecological restoration (Arts et al. 2016; Prior and Ward 2016).

Continuing to evolve since its introduction in the late 1990s (Soule and Noss 1998; Foreman 2004; Taylor 2005), this growing movement has provided a plural and, for some, confusing multiplicity of agendas (Jørgensen 2015). Broadly speaking, some differences originate from divergent ontologies of wild(er)ness and the historic influence of humans in co-producing 'natural' landscapes (Drenthen 2018; Ward 2019). This can distinguish North American and

\begin{tabular}{|l|l|}
\hline \multicolumn{2}{|c|}{ Access this article online } \\
\hline Quick Response Code: & Website: \\
\hline & www.conservationandsociety.org \\
\cline { 2 - 3 } & \\
\hline & \\
\hline
\end{tabular}

European forms of rewilding, the latter of which provides the geographical focus for this collection. The aim of creating healthier, more resilient, and largely self-willed ecosystems is, however, apparent as a unifying agenda (Gammon 2018; Pettorelli et al. 2018) moving away from the compositionalist and territorialised strategies of traditional conservation, towards a focus on ecological functionality and processes (Sandom et al 2013; Lorimer et al. 2015; Jepson 2016).

Despite much excitement and promise, rewilding continues to bristle with theoretical and practice-based tensions, underpinned by profound ontological and epistemological questions (Jørgensen 2015; Lorimer 2015). Critical scholars have questioned the shifting dynamics of power and governance involved, how these are enfolded in novel spatial and temporal framings, and the ethical and justice implications for both human-human and human-nonhuman relations. This includes work on the fraught biopolitics of rewilding (Lorimer and Driesson 2013, 2014, 2016); governance of official and unofficial species reintroductions (Crowley et al. 2017); diverging views of wildness, naturalness and place (Deary and Warren 2017, 2018); temporal and visual aesthetics (Prior and Brady 2015); intersections with rural transitions (Hearn et al. 2014; Navarro and Pereira 2015); vulnerabilities of communities and reintroduced species (Vasile 2018); relationships between cultural traditions and nonhuman autonomy (DeSilvey and Bartolini 2018); and the potential for justice and remediation in instances of conflict (Wynne-Jones et al. 2018).

In this special issue, we ask whether rewilding is simply a new 'trend' in conservation, which we can understand through existing frameworks, or whether it manifests a more substantive reworking of how we think and live with others. A

Copyright: (C) Wynne-Jones, et al. 2020. This is an open access article distributed under the terms of the Creative Commons Attribution License, which permits unrestricted use and distribution of the article, provided the original work is cited. Published by Wolters Kluwer - Medknow, Mumbai | Managed and supported by the Ashoka Trust for Research in Ecology and the Environment (ATREE), Bangalore. For reprints contact: reprints@medknow.com 
central set of questions which this collection takes forward is whether rewilding allows for a fundamentally new framework for human and non-human relatedness with space afforded to non-human autonomy or if, instead, it is an untenable paradox of 'controlled decontrolling' (Keulartz 2012) wherein conservation remains bound as an agenda of governance. We ask how new modalities of (de)control are being assembled and operationalised, exploring the role and interrelations of different actors/actants there in. We also ask how rewilding, as a mode of biopolitics, might manifest in careful or harmful practices, reworking existing values and ethics. Furthermore, we extend this to consider how these emerge in response to rewilding processes outside of conservation regimes, as well as those curated from within. In exploring whether rewilding is changing how we understand conservation governance and species co-habitation, the papers in this collection interrogate the utility and fit of current theories of conservation relating to power and control; new spatialities, and future ecologies. We outline these three dimensions below.

\section{DISRUPTING POWER AND CONTROL?}

The question of how power and agency are understood, distributed, and potentially reconfigured is of longstanding interest for critical scholarship in conservation, wildlife governance and multispecies relations (Philo and Wilbert 2000; Tsing 2005; Adams and Hutton 2007; Brockington et al. 2012; Buller 2014; Van Dooren et al. 2016; Larsen and Brockington 2018. This provides a wealth of theories and interdisciplinary perspectives, which papers in this collection draw upon. Perhaps, most notably, Foucault's theories on biopolitics, governmentality and the 'government of things' (Foucault 1991, 2008) have increasingly been applied to the management of nonhuman life (Lemke 2015). By mobilising scientific knowledge and employing mechanisms such as species lists and the concept of biodiversity, compositionalist conservation has demarcated, ordered and valued nature at both a species-population scale and through the bodies of individuals (Biermann and Mansfield 2014; Braverman 2015).

Differing modes and coalitions of bio- and disciplinary- power have been employed to foster desirable life (Schlosser 2008; Youatt 2008; Biermann and Mansfield 2014), and are enacted through practices that can be simultaneously caring and harmful to individuals in the name of the conserved collective (Srinivasan 2014; Van Dooren 2014). Here-in conservation and biosecurity often figure as interwoven or parallel agendas. Such practices of control, focussed on the species and multispecies assemblages that make up 'biosocial collectivities' (Rabinow and Rose 2006), are also used to 'abnormalise' undesirable species and demarcate them as 'killable' (Braverman 2015; Biermann and Anderson 2017).

Within this collection, the demarcation of life as protected or 'made killable' is a subject of discussion for papers by Clancy and Ward; O'Mahony; Ward and Prior, who evaluate the ways in which the lives of birds, boars and beavers (respectively) are ranked, ordered and regulated according to measures such as breeding and physiology, the extent and locations of territory, and behavioural dynamics. Reintroduction is a central feature of the rewilding movement, to enable the enhancement of trophic complexity and enrich depleted system dynamics (Svenning et al. 2016), but it is a fraught objective.

The papers highlight the hierarchies of human-value at play in determining how the lives of these animals are celebrated or contested, but also illuminate the unruly agency of the more-than-humans in question, identifying them as subject-objects (rather than static objects) of rewilding. In making this identification, we acknowledge more-than-humans in the co-production of future rewilded environments. The ultimate enhancement and, indeed, a celebration, of natures' agency is highlighted in papers by Holmes et al. and Wynne-Jones et al. as a unifying principle for the projects and practitioners they review, strengthening earlier assessments which have sought to distinguish the defining features of rewilding amidst much reformulation and confusion.

The collection explores how relations of power flow and are formulated within rewilding discourse and practice. Continuing with the theme of Foucauldian-inspired analysis, governmentality and more specifically, environmentality (Agrawal 2005; Fletcher 2010), have been used to explore the different ways in which powerful actors represent, subjectify and intervene in the conduct and capacities of governable others (Rutherford 2007; Fletcher 2017). However, the efficacy of governance should be seen as incomplete and compromised by the messiness of social relations. Indeed, a multiplicity of environmental publics (Eden 2016) with differing philosophies of nature means that the power, knowledge claims and circulating epistemologies of authoritative actors will always be contested.

The contributions identify how different regimes of knowledge, particularly those that might monopolise rewilding discourse and practice, are entangled, and accepted or rejected. Papers by Holmes et al. and Wynne-Jones et al. bring attention to this through broader comparative review of multiple actors and projects. The cases analysed by Clancy and Ward; O’Mahony; and Ward and Prior highlight not only a contestation of desires and agendas, but also the politics of uncertainty and incomplete knowledge - with much still unknown about the outcomes of rewilding.

There is a strong focus on how notions of 'wildness', and 'autonomous nature', encompass different ideas of control; what relations, species and practices should be subject to control, or whose presence (both human and non-human) is desirable or not. The contributions engage with ontological arguments about what wild is and how it is demarcated. They also explore the institutional parameters that delimit particular manifestations (or otherwise), including the influence of funding frameworks and associated reporting, along with legal definitions of species status. Pushing back against the restrictions of binary imaginaries, the papers explore wildness in terms of autonomy and self-sustenance (Woods 2005; Prior and Brady 2016), and as a 'relational achievement' (Whatmore and Thorne 1998), enabling the authors within the collection to 
re-approach questions about what, when, and where rewilding is appropriate, and how it should be carried out.

Holmes et al. and Wynne-Jones et al. in particular show how practitioners and advocates are responding and reworking some of the more problematic framings identified in early analyses, attempting to tackle tensions of social and interspecies justice (c.f. Wynne-Jones et al. 2018). Yet despite the promise of new imaginaries, there are continuing difficulties with, for example, the dynamic of human presence as both an undermining and necessary component; or in regard to conceptions of 'nativeness' and resultant legitimacy (discussed notably by O'Mahony). A key question determining distinctions in these framings is where the discourses of power are centred and decisions about practices made. The papers draw attention to these discourses by revealing the stories and agents behind specific interpretations, showing both the novelty and longevity in the groupings and stated concerns.

As noted above, power is not only a human achievement. Rewilding's celebration of the fecundity of life and the dynamism of interspecies relations brings the collection into conversation with post-human thinking on relational assemblages, emergent life and intermingling materialities (Deleuze 1987; Whatmore 2002; Bennett 2009; Ingold 2011). The papers move beyond Foucauldian-informed assessments of how explicitly human agendas are advanced, presenting a politics of the social as co-constituted by human and nonhuman agencies, animate beings and inanimate materials, in constant states of becoming in relation to, or with (Haraway 2008), each other. Rewilding thus appears to seek ways of giving 'more-than-human socialities' (Tsing 2013) the opportunity to unfold in emergent and inventive ways (Braun 2008), which challenge notions of a pre-existing and pure nature in need of preservation. This is particularly so with the explorations of 'auto-' and unintentional rewilding covered in the papers by Clancy and Ward; O'Mahony; Ward and Prior, where the animals in question disrupt tidy categorisation and associated conservation pathways and timelines refute easy starting points. Other papers show that by valuing the relational contributions of nonhuman beings to ecological functioning and world-making, as opposed to the intrinsic values of species in themselves, rewilding offers new aesthetics, ethics and understandings of belonging (Lorimer and Driessen 2013; Prior and Brady 2015) - notwithstanding the intractability of some framings (such as nativeness) considered above.

The cases presented reveal that (re)introduction and encounters with extirpated, surrogate or once maligned species, can establish new physical and moral boundaries - notably complicated by the dynamic of intentionality and legality. Deeply embedded philosophies and practices are unsettled (Buller 2008), and affective responses to new and unfamiliar companions can lead to diverse (often difficult) experiences (Lorimer 2012); for example, as we encounter their noises and smells, consumption, excreta and home-making behaviours. There are questions about the 'proper' behaviour of different animals, and how we determine this according desires and frameworks like 'ecological health', 'balance' and 'messiness'.
The welfare of rewilded animals in these emerging scenarios is fraught as questions over how wild animals are permitted to be(come) (von Essen and Allen 2016), and what qualities of wildness are seen to be most desirable. For example, contrasting an appreciation of charisma (Lorimer 2007), or even fear (Monbiot 2013), with nuisance (Van Dooren 2011). Nonetheless, despite the difficulties witnessed, this collection suggests that by taking the ethical 'work' involved in rewilding seriously we could expand our scope for living with animal-others in an increasingly human-dominated world (Plumwood 1993; Collard et al. 2015; Gibson et al. 2015).

\section{NOVEL SPATIALITIES}

In reworking the many facets of human-nonhuman relatedness and exercise of power, rewilding challenges the established spatialities and geographies of conservation governance. Conservation has generally been understood as a territorialised placing of nature that requires control, ownership, and bordering; fixing particular nonhumans (and indeed humans) to designated places (Hinchliffe 2007; Whatmore 2002). Spatially conservation often reaffirms an ontological separation of nature from human culture. In contrast, projects discussed complicate the forms of separation previously associated with discourses of 'the wild', both in their proximity to human populations and intention to accommodate (and in some cases even foster) contact between human-non-humans.

The European context of a densely human-populated and culturally-layered landscape undoubtedly comes into play here (Drenthen 2018). This has led to earlier analyses emphasising the necessity of rewilding within bounded sites, framing projects as individual ecological experiments within restricted spatial settings (Lorimer and Driessen 2013; Jepson 2016). Reliance on boundaries and boundedness does not however resolve the tensions that persist between the inside and outside, the included and excluded. Restricting species movements, mobilities, and autonomy, has led to welfare and ethical controversies (Lorimer and Driessen 2013), which many of the papers presented here similarly observe. Conversely, unrestricted (and indeed unanticipated) reintroductions, like those discussed in this collection, broaden the rewilded landscape and bring multiple actors/actants into contact in ways that might challenge understandings of human and nonhuman space (Philo and Wilbert 2000; Buller 2008; Drenthen 2015). Whilst the papers challenge previous demarcations by evidencing more unruly ecologies beyond tightly defined boundaries, it is apparent that humans continue to struggle with - and consequently wish to emplace - the 'lively' nonhuman actors in question.

Governance and efforts towards non-governance therefore remain spatially delimited, even where boundaries are porous or conceptual rather than concrete. The engagement with 'unofficial' and unintentional wilding in this collection is particularly informative in this regard, moving beyond the more authorised focus of previous studies. The papers explore how and with what mechanisms and processes these 
persisting boundaries are formed and related. This is an epistemological enquiry into the ways that nature becomes known, whilst also addressing the materiality of (non) management. Clancy and Ward's contribution, for example, points to ways that could 'hold open space', allowing 'out of place animals to make life anew', offering a critical insight on how (non)intervention and autonomy could be reconceptualised to work through a fundamental paradox of the rewilding movement (DeSilvey and Bartolini 2018). Furthermore, Ward and Prior argue that autonomy should not be used as a boundary marker to denote 'wild' nonhumans but as a situated condition that is variable across locations. They offer an empirical study of different expressions of non-human autonomy at two different locations in Scotland, where beavers have been reintroduced. Their findings reveal how, depending on location and context, modes of governance related to rewilding strategies co-exist and interplay with animal autonomy and forms of power in contradictory ways.

Linked to this emphasis upon emergence and the unexpected, several contributors to the issue show how new spaces of value are being created beyond established borderlines of conservation territory. Clancy and Ward's discussion of urban wilds and Wynne-Jones et al. and O'Mahony's events happening outside of current protected area sites and networks are of particular relevance. They show how the rich histories and multiple transformations of sites can produce a liberating openness and sense of flexibility to value judgements and management decisions, connecting with the themes of temporality considered below.

\section{ANTICIPATORY ECOLOGIES}

A final concern of this collection is with 'aspirant ecologies' (Parkes 2006), that is to say, the issue of temporality and the framing of rewilding as fundamentally future-orientated, and yet necessarily uncertain. There is an anticipatory logic which applies both to the timescales envisaged for rewilding goals to come to fruition and in the offer of more optimistic and flourishing ecologies within the uncertainty of the Anthropocene (Holmes 2015; Tsing 2017). This challenges the temporal scales familiar to the compositionalist modes of conservation which can act as a defensive protectionism of the past (Jepson 2018). Rewilding, in contrast, regards ecosystems as highly dynamic, complex and unpredictable. Moreover, our increasingly urban environments are 'novel ecosystems' which have no 'natural' analogues or points of comparison to inform conservation management decisions (see Scoones 1999; Zimmerer 2000; Hobbs et al. 2009; Manning et al. 2009).

The studies of Holmes et al. and Wynne-Jones et al. in this collection show that rewilding projects and protagonists have been highly critical towards past conservation baselines, questioning the intellectual basis of fixity as a desirable, or even feasible, objective and arguing that irreversible change is something we need to live with. These insights affirm the assessments of some earlier analyses (Lorimer 2015) and respond to the concerns of rewilding critics (Jorgenson 2015). The contributions also do not conflate rewilders' relationship with the past with the more radically future-centric position of the 'new conservation' movement (Kareiva et al. 2012). Whilst lost ecosystems are not romanticised or constructed as a blueprint, the ethical commitments of rewilders, in many instances, does seem to be informed by a sense of loss.

Another key issue addressed by the contributions is whether rewilders' emphasis upon uncertainty challenges or complies with the pre-emptive and anticipatory practices employed to securitise societal futures (Anderson 2010; Amoore 2013). This relates to how risk is conceptualised by different humans, and how such conceptualisations are subsequently deployed and experienced. Compositionalist conservation and wildlife management practices, as we outlined earlier, can be seen as forms of biosecurity, which seek to order and spatially control risky lives and bodies (Bingham et al. 2008; Barker 2015; Hinchliffe et al. 2013. While both compositionalist and rewilding practices approach the exercise of power and human need to either constrain or withdraw from wilding influences, the papers highlight limitations to human agency and even human knowledge of likely outcomes.

In terms of 'anticipatory ecologies', rewilding contends that power should be exercised to facilitate ecosystemic processes that have no predetermined outcomes. Rewilding advocates call for letting go in the face of unavoidable uncertainty and maintaining a lighter, more experimental framework of control. This contention brings us full circle, returning to our opening question of whether rewilding changes understandings of the extent to which conservationists can govern, how they can govern or if, more fundamentally, it is a process that could undermine the project of governance.

Paradoxically, in seeking to loosen control, rewilding highlights how much ordering and management is at the heart of the conservation project. It reframes the focus of conservation on the enchanting possibilities of multispecies kinship and the difficulties of co-existing, learning and exploring less ordered more-than-human worlds. It emphasises both the need for respect and admission, and a more compassionate understanding of the complex histories, trajectories, vulnerabilities and threats of co-existence.

The contributions to this special issue highlight how rewilding is an admission of human limits and not just a step back from dominance. Rewilding as an approach values abundance, fecundity, and emergent everywhere, though, critically, in relation and according to context. In so doing, it calls on us to seriously rethink what we know about ecology and the project of doing conservation.

\section{REFERENCES}

Adams, W.M. and J. Hutton. 2007. People, parks and poverty: political ecology and biodiversity conservation. Conservation and Society 5(2): 147-183.

Agrawal, A. 2005. Environmentality: technologies of government and political subjects. Durham: Duke Press. 
Anderson, B. 2010. Preemption, precaution, preparedness: anticipatory action and future geographies. Progress in Human Geography 34(6): 777-798.

Amoore, L. 2013. The politics of possibility: risk and security beyond probability. Durham: Duke University Press

Arts, K., A. Fischer, and R. van der. 2016. Boundaries of the wolf and the wild: a conceptual examination of the relationship between rewilding and animal reintroduction. Restoration Ecology 24(1): 27-34.

Barker, K. 2015. Biosecurity: securing circulations from the microbe to the macrocosm. The Geographical Journal 181(4): 357-365.

Bennett, J. 2009. Vibrant matter: a political ecology of things. Durham: Duke University Press.

Bingham, N., G. Enticott, and S. Hinchliffe. 2008. Biosecurity: spaces, practices, and boundaries. Environment and Planning A 40(7): 528-533.

Biermann, C.and R.M. Anderson. 2017. Conservation, biopolitics, and the governance of life and death. Geography Compass 11(10): 1-13.

Biermann, C. and B. Mansfield. 2014. Biodiversity, purity, and death: conservation biology as biopolitics. Environment and Planning D: Society and Space 32(2): 257-273.

Braverman I. 2015. Wild life: the institution of nature. California: Stanford University Press.

Braun, B. 2008. Environmental issues: inventive life. Progress in Human Geography 32(5): 667-679.

Brockington, D., R. Duffy, and J. Igoe. 2012. Nature unbound: conservation, capitalism and the future of protected areas. Oxford: Routledge.

Buller, H. 2008. Safe from the wolf: biosecurity, biodiversity, and competing philosophies of nature. Environment and Planning $A$ 40(7) 1583-1597.

Buller, H. 2014. Animal geographies I. Progress in Human Geography 38(2): 308-318.

Collard, R.C., J. Dempsey, and J. Sundberg. 2015. A manifesto for abundant futures. Annals of the Association of American Geographers 105(2): 322-330.

Crowley, S. L., S. Hinchliffe, and R.A. McDonald. 2017. Nonhuman citizens on trial: the ecological politics of a beaver reintroduction. Environment and Planning A 49(8): 1846-1866.

Deary, H. and C.R. Warren. 2017. Divergent visions of wildness and naturalness in a storied landscape: practices and discourses of rewilding in Scotland's wild places. Journal of Rural Studies 54: 211-222.

Deary, H. and C.R. Warren. 2018. Trajectories of rewilding: a taxonomy of wildland management. Journal of Environmental Planning and Management 62(3): 1-26.

Deleuze, G. and F. Guattari. 1987. A thousand plateaus. London: Continuum Series. Bloomsbury.

De Silvey, C. and N. Bartolini. 2018. Where horses run free? autonomy, temporality and rewilding in the Côa Valley, Portugal. Transactions of the Institute of British Geographers 44(1): 94-109.

Drenthen, M. 2015. The return of the wild in the anthropocene. wolf resurgence in the Netherlands. Ethics, Policy \& Environment 18(3): 318-337.

Drenthen, M. 2018. Rewilding in culturally layered landscapes. Environmental Values 27: 325-330.

Eden, S. 2016. Environmental publics. Oxford: Routledge.

Fletcher, R. 2010. Neoliberal environmentality: towards a poststructuralist political ecology of the conservation debate. Conservation and Society 8(3): 171-181.

Fletcher, R. 2017. Environmentality unbound: multiple governmentalities in environmental politics. Geoforum 85: 311-315.

Foreman, D. 2004. Rewilding North America: a vision for conservation in the 21st century. Washington D.C: Island Press.

Foucault, M. 1991. Governmentality. In: The Foucault effect: studies in governmentality (eds. Burchell, G., C. Gordon, and P. Miller). Pp. 87-104. Hemel Hampstead: Harvester Wheatsheaf.

Foucault, M. 2008. The birth of biopolitics. New York: Palgrave MacMillan.
Gammon, A. 2018. The many meanings of rewilding. Environmental Values 27: $331-340$

Gibson, K., D.B. Rose, and R. Fincher. 2015. Manifesto for living in the Anthropocene. New York: Punctum Books.

Haraway, D.J. 2008. When species meet. Minneapolis: University of Minnesota Press.

Hearn, R., C. Watkins, and R. Balzaretti. 2014. The cultural and land use implications of the reappearance of the wild boar in North West Italy: a case study of the Val di Vara. Journal of Rural Studies 36: 52-63.

Hinchliffe, S. 2007. Geographies of nature: societies, environments, ecologies. London: Sage.

Hinchliffe, S., J. Allen, S. Lavau, N. Bingham, and S. Carter. 2013. Biosecurity and the topologies of infected life: from borderlines to borderlands. Transactions of the Institute of British Geographers 38(4): 531-543.

Hobbs, R., E. Higgs, and J. Harris. 2009. Novel ecosystems: implications for conservation and restoration. Trends in Ecology \& Evolution 24(11): 599-605.

Holmes, G. 2015. What do we talk about when we talk about biodiversity conservation in the anthropocene? Environment and Society 6(1): 87-108.

Ingold, T. 2011. Being alive: essays on movement, knowledge and description. Oxford: Routledge.

Jørgensen, D. 2015. Rethinking rewilding. Geoforum 65: 482-488.

Jepson, P. 2016. A rewilding agenda for Europe: creating a network of experimental reserves. Ecography 39(2): 117-124.

Jepson, P. 2018. Recoverable Earth: a twenty-first century environmental narrative. Ambio 48(2): 1-8.

Kareiva, P., R. Lalasz, and M. Marvier. 2012. Conservation in the Anthropocene: beyond solitude and fragility. love your monsters: postenvironmentalism and the anthropocene. winter. Oakland, California: Breakthrough Institute.

Keulartz, J. 2012. The emergence of enlightened anthropocentrism in ecological restoration. Nature and Culture 7(1): 48-71.

Larsen, P.B. and D. Brockington. 2018. The Anthropology of conservation NGOs. Cham: Palgrave Macmillan.

Lemke, T. 2015. New materialisms: Foucault and the 'government of things'. Theory, Culture \& Society 32(4): 3-25.

Lindenmayer, D.B. and J. Fischer. 2013. Habitat fragmentation and landscape change: an ecological and conservation synthesis. New York: Island Press.

Lorimer, J. 2007. Nonhuman charisma. Environment and Planning D: Society and Space 25(5): 911-932.

Lorimer, J. 2012. Multinatural geographies for the Anthropocene. Progress in Human Geography 36(5): 593-612.

Lorimer, J. 2015. Wildlife in the Anthropocene: conservation after nature. University of Minnesota Press.

Lorimer, J. and C. Driessen. 2013. Bovine biopolitics and the promise of monsters in the rewilding of Heck cattle. Geoforum 48: 249-259.

Lorimer, J. and C. Driessen. 2014. Wild experiments at the Oostvaardersplassen: rethinking environmentalism in the Anthropocene. Transactions of the Institute of British Geographers 39(2): 169-181.

Lorimer, J. and C. Driessen. 2016. From "Nazi cows" to cosmopolitan "ecological engineers": specifying rewilding through a history of Heck cattle. Annals of the American Association of Geographers 106(3): 631-652.

Lorimer, J., C. Sandom, P. Jepson, C. Doughty, M. Barua, and K.J. Kirby. 2015. Rewilding: science, practice, and politics. Annual Review of Environment and Resources 40: 39-62.

Manning, A., J. Fischer, A. Felton, B. Newell, W. Steffen, D. Lindenmayer, and K. Parr. 2009. Landscape fluidity: a unifying perspective for understanding and adapting to global change. Journal of Biogeography 36(2): 193-199. 
76 / Wynne-Jones, et al.

Monbiot, G. 2014. Feral: Rewilding the land, the sea, and human life. Chicago: University of Chicago Press.

Navarro, L.M. and H.M. Pereira. 2015. Rewilding European Landscapes. Cham: Springer.

Parkes, P. 2006. Aspirant ecologies: a geography of rewilding in England and Wales. Ph.D. thesis. University of Nottingham, Nottingham, UK.

Pettorelli, N., J. Barlow, P.A. Stephens, S.M. Durant, B. Connor, H. Schulte to Bühne, C.J. Sandom, et al. 2018. Making rewilding fit for policy. Journal of Applied Ecology 55(3): 1-12.

Pettorelli, N., S. Durant, and J. Du Toit (eds). 2018. Rewilding. Cambridge University Press.

Philo, C. and C. Wilbert. 2000. Animal spaces, beastly places: new geographies of human animal relations. London: Routledge.

Plumwood, V. 1993. The politics of reason: towards a feminist logic. Australasian Journal of Philosophy 71(4): 436-462.

Prior, J. and E. Brady. 2016. Environmental aesthetics and rewilding. Environmental Values 26(1): 31-51.

Prior, J. and K.J. Ward. 2016. Rethinking rewilding: a response to Jørgensen. Geoforum 69: 132-135.

Rabinow, P. and N. Rose. 2006. Biopower today. BioSocieties 1(2): 195-217.

Rutherford, S. 2007. Green governmentality: insights and opportunities in the study of nature's rule. Progress in Human Geography 31(3): 291-307.

Sandom, C., C.J. Donlan, J.C. Svenning, and D. Hansen. 2013. Rewilding. In: Key topics in conservation biology 2 (eds. Macdonald, D. and K. Willis.). Pp. 430-451. Chichester: Wiley-Blackwell.

Sandom, C. and S. Wynne-Jones. 2018. Rewilding a country: Britain as a case study. In: Rewilding (Pettorelli, N., S. Durant, and J. DuToit). Cambridge: Cambridge University Press.

Schlosser, K. 2008. Bio-political geographies. Geography Compass 2(5): $1621-1634$.

Scoones. 1999. New ecology and the social sciences: what prospects for a fruitful engagement. Annual Review of Anthropology 28(1): 479-507.

Soule, M. and R. Noss. 1998. Rewilding and biodiversity: complementary goals for continental conservation. Wild Earth 8: 18-28.

Svenning, J.C., P.B.M. Pedersen, C.J. Donlan, R. Ejrnaes, S. Faurby, M. Galetti, D.M. Hansen, et al. 2016. Science for a wilder Anthropocene: synthesis and future directions for trophic rewilding research. Proceedings of the National Academy of Sciences of the United States of America 113: 898-906.
Srinivasan, K. 2014. Caring for the collective: biopower and agential subjectification in wildlife conservation. Environment and Planning D: Society and Space 32(3): 501-517.

Tsing, A. 2005. Friction: an ethnography of global connection. Princeton NJ: Princeton University Press.

Tsing, A. 2013. More-than-human sociality: a call for critical description. In: Anthropology and nature (ed. Hastrup, K). Pp. 27-42. New York: Routledge.

Tsing, A. L., N. Bubandt, E. Gan, and H. Swanson. 2017. Arts of living on a damaged planet: Ghosts and monsters of the Anthropocene. Mineapolis: University of Minnesota Press.

Vasile, M. 2018. The vulnerable bison: practices and meanings of rewilding in the Romanian Carpathians. Conservation and Society 16(3): 217-231.

Van Dooren, T. 2011. Invasive species in penguin worlds: an ethical taxonomy of killing for conservation. Conservation and Society 9(4): 286-298.

Van Dooren, T. 2014. Flight ways: life and loss at the edge of extinction. New York: Columbia University Press.

Van Dooren, T., E. Kirksey, and U. Münster. 2016. Multispecies studies: cultivating arts of attentiveness. Durham: Duke Press.

von Essen, E. and M. Allen. 2016. Wild, but not too-wild animals: challenging Goldilocks standards in rewilding. Between the Species 19(1): 4.

Vera, F. 2000. Grazing ecology and forest history. Wallinford: CABI Publishing.

Whatmore, S. 2002. Hybrid geographies: natures cultures spaces. London: Sage.

Whatmore, S. and L. Thorne. 1998. Wild (er) ness: reconfiguring the geographies of wildlife. Transactions of the Institute of British Geographers 23(4): 435-454.

Woods, M. 2005. Ecological restoration and the renewal of wildness and freedom. In: Recognizing the autonomy of nature: theory and practice (ed. Hryd, T.). Pp.170-188. New York: Columbia University Press.

Wynne-Jones, S., G. Strouts, and G. Holmes. 2018. Rewilding in Wales: reimagining or abandoning a cultural heartland? Environmental Values 27: $377-403$

Youatt, R. 2008. Counting species: biopower and the global biodiversity census. Environmental Values 17(3): 393-417.

Zimmerer, K. S. 2000. The reworking of conservation geographies: nonequilibrium landscapes and nature-society hybrids. Annals of the Association of American Geographers 90(2): 356-369. 